\title{
HEREDITY IN DISEASE ${ }^{1}$
}

\section{By G. Archdall Reid, M.B., F.R.S.Edin., Southsea.}

THE human body, like that of all the higher plants and animals, is a cell-community. The cells are mostly adherent, and all have descended from a common ancestor, the fertilised ovum; but in a very real sense every cell is a distinct and separate living entity, a unicellular animal. Blood-cells are free, germ-cells are purely parasitic, skin-cells have often been transplanted; there is little doubt that had we the requisite skill it would be possible to transplant every other kind of cell. No single cell in the body is the offspring of any other co-existing cell or group of cells, but every cell is derived from a pre-existing cell. Omnis cellula e cellulâ. The whole cell-community is separable into two distinct but very unequal parts : into germ-cells, and systemic (somatic) cells. To the former belong the function of continuing the race, to the latter the function of protecting the all important germ-cells.

A few years ago it was universally believed that acquired characters were transmissible. It was thought that changes in body and mind -caused by exercise, disease, accident, or what not-affected the germ-cells in such a special manner, that the traits the parent acquired tended to reappear as inborn characters in the child. At the present day the majority of those who have given real scientific attention to the question believe the contrary. The problem is of obvious importance to medical men, who, however, as a body have curiously neglected it. Before beginning its discussion it is necessary to define a couple of terms, the loose use of which has resulted in endless confusion.

An inborn character may be defined as one which results in the individual from the constitution of the germ-cell (or pair of germcells) whence he sprang. Thus a man's ears, eyes, nose, etc., are inborn characters. They arise because his germ is so constituted that under fit conditions of shelter, nutrition, etc., it tends to proliferate into an organism having those characters. An acquired character, on the other hand, is one which results from the action of the environment on the soma-the systemic or body cells as distinguished from the germs. Hence all characters produced in the individual by modes of life, by exercise, disease or accident, are acquirements. To take an example, suppose the child of a normal man is blind; then the blindness is inborn if due to a defect in the germ whence the child sprang, but acquired if due to disease or accident to his visual structures after they have developed from the germ. The error is often made of supposing that all new characters are acquirements. Thus a supernumerary digit on its first appearance in a family is often spoken of as one. It must, however, be clearly borne in mind that the distinction between the inborn and the acquired is not one between the old and the new; it is wholly one of origin. Inborn characters originate in the germ-cell; acquired characters in its descendants, the somatic cells. As a fact, every character acquired or inborn is new to every individual who has it ; thus a man's head is

1 Reprinted from the "Scottish Medical and Surgical Journal," June 1900. 
as much a novelty to him as a supernumerary digit. Every child differs somewhat from its parent. When a difference is inborn (i.e. when it is due to a germinal peculiarity), it is technically termed a "variation." All acquirements, on the other hand, are termed "modifications." It should be noted that a modification (unlike a variation) does not necessarily imply a difference from the parent; both parent and child may acquire similar modifications. The cause of variation is yet a matter of dispute. Many elaborate theories have been enunciated, which, at the least, afford splendid testimony to the imaginations of their authors. We need not dwell on them; suffice it to say that variations do occur, no matter how produced. Men do differ in inborn characters from their parents.

The body, as I say, is a cell-community, composed of germs and other cells. Now suppose a man acquires a character; suppose, for instance, he strengthens his arms by exercise, or weakens his legs by laziness, then, if his acquired character is to be transmitted, the change in his arms or legs must so affect his germs, that it will be reproduced (as an inborn character) in the children into which the germs proliferate. This consideration at once reveals the difficulty of all belief in the transmission of acquired characters. How can each one of the million changes which may occur in the arms, legs, and other parts of the body affect the germs (situated it may be far distant) in such a special manner that after fertilisation and long separation from the parent organism the germs will proliferate into beings that have inborn the particular character the parent acquired? How, for example, can a modification of the parent's great toe affect his germ differently from a modification in his little finger? What is the machinery by which this magical process is carried out? $A$ priori, therefore, the transmission of acquirements seems impossible ; or at least so highly improbable that only the clearest evidence should satisfy us. Is such evidence forthcoming? It is a simple fact that though the whole plant and animal world has been ransacked, no single instance of the transmission of a single acquired character has yet been proved. It is easy to say that important changes, such as those caused by constant hard exercise or continual laziness, must affect the germs, and through them the offspring. All that is not denied. It is the particular effects which are denied. It is not denied, for example, that the exercise which strengthens the arms, or the laziness which injures the legs, may, through changes in the nutrition, in some way or other, for good or evil, affect the germs; it is only denied that the arms or legs of the child will be affected more especially than the lungs or the liver. Indeed we may go even further and say that, while it is theoretically possible for acquired characters to affect the germ, this is not known to be true ; for instance it is not known what effect, if any, exercise or laziness has on the germs. All that can be postulated with certainty is that acquired characters do not so affect the germ that the child inherits the precise peculiarity the parent acquired, or anything like it.

The modern denial of the transmission of acquirements is really founded on, or should be founded on, the cell theory. Before its enunciation the different parts of the offspring were supposed to be derived from similar parts of the parent. Man, for example, was regarded as an individual. We know now that from the standpoint 
of heredity he is a community - a community of specialised cells-of which one set, the germs, are specialised for the production of similar cell-communities, just as other sets are specialised for the production of motion or of bile. We have therefore no more reason to suppose that muscle or liver cells play a part in heredity than to suppose that the germ-cells play a part in movement or in the production of bile. Formerly, when the transmission of acquirements was believed without question, some remarkable hypotheses to account for the supposed transmission were formulated, occasionally by very distinguished men. Darwin's theory of Panganesis and Spencer's theory of Physiological Units are examples. These speculations were what are known as "working hypotheses"-hypotheses, that is, in which the amount of theory, perhaps I should say guess work, is wholly disproportionate to the foundation of fact, and which a more extended acquaintance with the facts usually reveals to be misleading. At the present day, when the transmission of acquirements is generally disbelieved, some working hypotheses, as remarkable, but running to the other extreme, have been formulated. Under very high powers of the microscope the nuclear matter of the fertilised germ may be seen to divide, apparently with great accuracy. On this slender foundation Weissmann has built his hypothesis of the continuity of the germ-plasm, adding amazing complications in the way of ids and idants and biophors, hypothetical bearers of heredity. Cheerfully entering into the regions of the unknown and probably the unknowable, he has attempted to explain how inborn characters are transmitted. Biologists in larger part have followed him.

His speculations, darkening counsel, crop up in every discussion on the subject. As a fact they have no essential bearing on it. The doctrine, first formulated by Galton, that acquired characters are not transmissible is one thing, and is supported by abundant evidence. An attempt, on obscure intracellular grounds, to explain how inborn characters are transmissible, even if it involves the corollary that acquired traits are not heritable, is quite another thing. If successful it would afford additional proof of the former doctrine; its failure does not involve disproof of it. Galton's theory rests on the plain facts that each individual is derived solely from a single cell, the germ; and that there is no evidence that the somatic cells influence the germs in such a special and unlikely manner as to cause the particular characters the parent acquired to be reproduced by the children. It does not rest on more or less metaphysical speculations concerning the continuity of the germ-plasm or of ids, idants, biophors and so forth. It is to be deeply regretted that this red herring of Weissmannism has been drawn across the trail. Weissmann's speculations, obscure in themselves, made more obscure by his methods of demonstration, still more obscure by being constantly amended under the influence of destructive criticism, have drawn many students from the true path, and by their difficulty have discouraged others. The actual issues involved are very simple. Either the germ-cells are influenced by the other cells in particular directions -in millions of particular directions-or they are not. Not a tittle of evidence has been adduced to prove that they are. In other words, no single instance of the transmissions of an acquired character has been recorded. 
The cell theory supplies us with cogent reasons for believing that acquired characters cannot be transmitted. To set forth in extenso the proofs that they are not transmitted would exceed the limits of this article, in which I have still to deal with the large subject of heredity in disease. One or two arguments I may use, however, partly because they have not to my knowledge been developed by other writers, and partly because they seem to me well-nigh decisive. The extra development of the blacksmith's arm is rightly called an acquired trait, since it arises from exercise, from use, not from germinal conditions. But no infant's arm develops into an ordinary adult arm without stimulation similar in kind to that which develops the blacksmith's arm, though less in degree. Therefore almost all that separates the infantile from the ordinary arm is acquired. The same is true of most of the other structures of the body, which do not develop except uncler the stimulation of use. Thus the brain, heart, lungs, all develop in this manner. Man's physical acquirements are therefore vast. When are any of them transmitted? Every infant has to make afresh under similar stimulation the modifications its parent so laboriously acquired. If it be argued that exercise and use increase, not only the individual's acquirements, but also his poiver of making them, and that it is the latter which is transmitted, I have only to reply that here is a manifest error. In the passage from infarıcy to old age the power of making acquirements constantly declines. In the infant it is at a maximum; hence his development into adult man. In the old man it is at a minimum; it is almost lost. Where nothing is acquired nothing can be transmitted. The same arguments apply to mind. At birth the infant's mind is a blank. His subsequent mental acquirements are immense. Every single thing contained within the memory of adult man, every single word of a language, for instance, is an acquirement. But when are the contents of a parent's mind transmitted to the child? Again a man is capable of becoming a parent at any time between extreme youth and cxtreme old age; a woman from the age of thirteen or fourteen till nearly fifty. Between the birth of the first child and the last such an individual changes vastly. Under the stress and tear of circumstances, under the slings and arrows of outrageous fortune, all sorts of acquirements are made. The body becomes vigorous and then feeble; the mind grows mature, and then senile. He or she grows wrinkled and bowed, and perhaps very wise, or perhaps much the reverse. Yet no one viewing a baby show, a children's party, or an assembly of adults, of whom he has no previous knowledge, can say which is the child of the youthful and which of aged parents. Apparently, therefore, the whole of the parents' acquirements have no effect on the child. Surely no arguments could be stronger.

It is true that some medical men maintain that the children of old men who have suffered from gout have a greater tendency to that disease than the children of younger men; but this is just one of those wild unconfirmed guesses with which medical literature unfortunately abounds. No statistical proof has been advanced. Post hoc has been confused with propter hoc. Men with a gouty diathesis, an inborn trait, tend under fit conditions to develop gout; inborn characters are transmissible; children are usually placed under conditions much the same as their parents, therefore gouty men 
often have gouty children. There is nothing to prove that the parental acquirement, the disease as distinguished from the diathesis, in any way affects the offspring. The poor Irish peasantry do not suffer from gout. When they have the diathesis it remains latent. Removed to richer food and easier conditions in English cities, they suffer on the average as much as other people. There is nothing in fact but guess work, mere opinions unsubstantiated by close and accurate observation, to show that the younger children of a gouty family are more liable to gout than the elder. Mutilations are sometimes instanced by medical men as affording examples of the transmissions of acquirements. Seeing, as they daily do, injuries caused by accident, disease, and the surgeon's knife, medical men should be peculiarly qualified to judge. In a million instances there is no apparent transmission. In the millionth and one a man with an amputated leg has perhaps a son with a deformed toe; thereupon the transmission of an acquirement is triumphantly proclaimed. There is, however, such a thing as mere coincidence. It is forgotten that though every mother loses her hymen and nearly every terrier his tail, yet congenital absence of hymen and tail is still so rare as to be regarded with extreme suspicion. Maternal impressions are much relied on. A mother sees a mutilated or malformed man, and it happens her child is malformed. Here again the element of coincidence is forgotten; every woman sees malformations during her pregnancy, but very few have malformed children. The children of nurses and lady doctors are not peculiarly liable to malformations. Moreover the mother gets a mental impression; the child something quite different, a physical malformation; therefore in any case there is no transmission of the mother's acquirement. Often, as in the case of gout, diathesis is confused with disease. Thus father and son both may have an inborn (and transmissible) incapacity to resist the bacillus of tuberculosis. They both get infected. Thereupon the son is supposed to have inherited consumption from the father. He merely inherits the incapacity to resist the bacillus. The acquirements, infection and disease, come later. Like the parent he acquires them for himself. Again, certain morbid conditions depending generally on structure are inborn, e.g. hæmophilia. The father, perhaps the first of his race to be so afflicted, transmits his inborn peculiarity, like other inborn traits, to the child. The new is then confused with the acquired, and the transmission of an acquirement is thought to be proved.

The debate on Heredity in Disease by the members of the Edinburgh Medico-Chirurgical Society, lately published in the Scottish Medical and Surgical Journal, was very interesting to the writer. Impressed by the importance of the subject, he has long hammered at it without awakening much interest. It is to be hoped Professor Hamilton will be more successful. It is in his favour that his audience, as proved in the subsequent debate, showed a grasp of the subject not very usual south of the Tweed, where the mention of heredity in medical circles provokes as a rule not argument but wrath. "Weissman's locomachy" is denounced, and contempt is expressed for the "philosophic froth which has been poured about." "Abstract Philosophy," we are told, is not of importance in medicine, which it ${ }^{1}$ Vide "The Present Evolution of MIen." (London: Chapman and Hall). 
seems is a science of "tips"-ipecac. is good for cough, chlorodyne is good for stomach-ache, and so forth. To judge by appearances, the comtempt in this case is not founded on familiarity.

A point of far-reaching importance, one which tells decisively in the controversy, was, however, left untouched by Professor Hamilton and those who followed him. If, as is alleged by most medical men, the effects of disease are transmissible, then these effects must accumulate generation after generation. The son must start with the parent's constitution plus the effects of the son's disease, and so on. It is plain on this hypothesis, that a race afflicted by any disease should undergo evolution or degeneration-evolution if the disease tends to strengthen the individual against subsequent attacks as by conferring immunity, degeneration if it tends to weaken him. On the other hand, if the effects are not transmissible, then a race afflicted by deadly disease would equally change, would undergo evolution-but not degeneration. For men differ in their inborn power of resisting disease. Disease is a selective agency. It weeds out the less resistant to it, leaving the race to the more resistant. Therefore on this hypothesis a race afflicted by disease should grow more and more resistant to it. Moreover, since resisting power against one disease does not imply resisting against any other, for example, since resisting power against phthisis does not imply resisting power against malaria, every race should grow resistant only against the particular diseases by which it is afflicted.

To some extent, to a very slight extent compared with its importance, this subject has engaged the attention of medical men, and always it has been supposed that when races change under the influence of disease they do so through the transmission of acquirements. Thus Dr William Russell remarks, "That acquired characters can be propagated there is strong proof. It is generally accepted that the two commonest diseases in this country, namely, scarlet fever and measles, are much less virulent than they used to be, and this is almost certainly to be attributed, not to an attenuation of the virus, or to improved treatment, but to a measure of immunity acquired by a population whose progenitors for generations have passed through the ordeal of these infections. It is a historical fact that measles introduced into a virgin soil, unmodified by a degree of immunity acquired by transmission, proves a most virulent and fatal malady. Another historical instance is that of the company of Esquimaux who, taken to Berlin, were vaccinated to prevent them taking smallpox, and they nearly all died from the modified virus used without any risk for protective purposes by the ordinary European." 1

Dr Russell's statement is certainly correct, but I think his deduction may be shown to be wrong. Moreover the extent and importance of the racial change mentioned by him is not often realised by medical men. All the races of mankind sprang from a common origin-Adam and Eve or a species of lower animal, it matters not which. But they have diverged vastly. There are big races and small, white and black, wooly and straight-haired, and so forth. Among other particulars, races differ greatly in their powers of resisting this or that disease. For example, negroes are incomparbly more resistant to malaria than Englishmen, who, on the other hand, are as highly resistant to tuberculosis when compared to

I The "Scottish Medical and Surgical Journal," April 1900, p. 330. 
Australian blacks. It is most significant that every race is resistant to every deadly disease strictly in proportion to its past experience of it. Englishmen and Polynesians, when emigrants in countries where malaria, typhoid, or dysentery are very rife, suffer much more than the native inhabitants. When small-pox, measles, tuberculosis, syphilis, scarlatina, plague, or yellow fever overpass their normal boundaries, and attack the inhabitants of countrics where they were previously unknown, or little known, they are destructive to a very unusual degree, as in Polynesia. Dr Russell mentions an interesting example. Vaccinia is presumably a very attenuated form of variola. For centuries and until very recently we were scourged by small-pox; to the Esquimaux it was unknown. Most of us are able to recover even from small-pox; the Esquimaux perish even from vaccinia.

One attack of many diseases on the individual increased resisting power, or even complete immunity, against subsequent attacks of the same disease, as in the case of scarlatina and chicken-pox. There is a consensus of medical opinion that this increase of resisting power in the parent is transmitted to some extent to the child, and that thus, from its accumulation during generations, arises increased resisting powers in the race. But there are some diseases, of which tuberculosis is an example, against which no resisting powers can be acquired. One attack of tuberculosis, a most death-dealing disease, weakens, rather than strengthens, against subsequent attacks. If, therefore, the acquired effects of disease are transmissible, races afflicted by tuberculosis should grow less and less resistant to it. The exact opposite is true. For very many centuries tuberculosis has ravaged the Old World, especially such crowded parts of it as England. But Englishmen now increase and multiply in cities and towns, the natural breeding places of tuberculosis, whereas, under like conditions, the inhabitants of the New World, where tuberculosis was unknown till recently, perish. When infected with tuberculosis by white men they tend to extinction everywhere, even in rural districts. Plainly their has been great evolution, but as plainly it has resulted solely from the survival of the fittest, not in the least from the transmission of acquirements. On the other hand there are some diseases against which immunity may be acquired, but which, though prevalent, are not deadly. Chicken-pox is an example. Against them no evolution is observable, for chicken-pox is as severe in type when attacking Polynesians as when attacking Englishmen. In this case, in the absence of selection, the acquirement of immunity has not tended to render the race more resistant. It is clear, then, that races grow resistant, not through the transmission of acquirements, but solely by the survival of the fit. ${ }^{1}$

1 It is to be noted that one attack of many diseases usually confers immunity on the individual, yet in such cases the race never attains to it. Each succeeding generation remains as susceptible to infection as the preceding. Thus Englishmen are as susceptible to infection by measles as Polynesians. But since measles weeds out those who cannot recover from it $(i . e$. , those who cannot acquire immunity from it), the direction the evolution takes is towards an increase of the pover of asquiring immunity. For that reason, though Englishmen are as susceptible to infection by measles as Polynesians, they recover from it much more easily. The only diseases against which inborn immunity is, or tends to be, evolved, are those against which the individual cannot acquire immunity-tuberculosis, for example. When immunity against disease can be acquired by the individual, then the power of acquiring it is evolved in the race by Natural Selection. When it cannot be acquired by the individual, when one attack weakens rather than strengthens, then inborn immunity is evolved in the race. In the one case the capacity to recover from infection is evolved; in the other the capacity to resist infection. In both cases the evolution proceeds wholly on lines of Natural Selection, not on lines of the transmission of acquirements. 
A study of alcohol and other narcotics is instructive in this connection. Indulgence in any of them - alcohol, for example, increases as a rule the desire for indulgence. The more a man drinks, the more within limits does he crave for drink. But the limits vary widely. In some men experience of drink quickly awakens a desire for deep indulgence. They have the alcoholic diathesis, an inborn trait. They become drunkards, unless withheld by moral or other deterrents. In other men experience of drink, no matter how prolonged, awakens nothing more than a desire for moderate indulgence. They have not the drink diathesis. They are temperate without effort all their lives. The reader probably belongs to the latter category; he is not tormented by a craving for drunkenness; he is therefore temperate, not because he resists temptation, but through lack of it. Yet even in his case indulgence has increased his desire for alcohol up to a certain point. Now this increased desire for drink, this increased capacity for enjoying it, this weakened capacity for resisting it, which springs from indulgence, is an acquired trait, and therefore, if acquired traits are transmissible, the race which has longest used drink should be the most inclined to drunkenness of all. The son would inherit the father's capacity for enjoying drink, plus the increment caused by the father's drinking; the grandson would in inherit the son's capacity, plus the increment caused by the son's drinking; and so on. It is evident that, given a sufficient supply of alcohol, the desire would at length grow so intense and uncontrolable that the race would be exterminated. On the other hand, since men differ in the intensity with which they crave for drink; since those who crave most, being exposed to the greater temptation, as a rule drink most; since alcohol is a poison which poisons most those who drink most; it must follow, if acquired characters are not transmitted, that this elimination of the unfittest and survival of the fittest will result at length in a lessened proneness to deep indulgence, to the elimination, in fact, of the drink diathesis, to the evolution of a more temperate race.

What are the facts? Neglecting temporary fluctuations, generally of minor importance, caused by changes in fashions, or morals, or in the price of alcohol, etc., every race that has access to abundant supplies of alcohol, is temperate strictly in proportion to its past experience of the poison. There has, in fact, been no transmission of an acquirement, but merely a great survival of the fittest. The Jews and the inhabitants of the wine countries generally, who have been afflicted by alcohol for thousands of years, are the most temperate peoples on earth. North Europeans, who have had a less abundant supply, and have been less afflicted and for a shorter period, are much more drunken. Savages, who have never been able to manufacture alcohol, are so inclined to drunkenness, that in all parts of the world, from pole to pole, when given the opportunity, they drink to extinction and perish. They are as little capable of persistence in the presence of strong modern solutions of alcohol as they are of persistence in towns in the presence of tuberculosis. It is the fashion to attribute national insobriety to all sorts of causes. To climate;-but savages in all climates are drunken, whereas Jews are sober. To strength of beverages;- but Wellington's English were drunken in the Peninsular 
when the native soldiers were sober; savages, if they have the opportunity, get drunk on the lightest beverages; the sober races of the present time, Jews, Greeks, South Germans and Frenchmen, Italians, Spaniards, and Portuguese, were anciently drunk when their wines were no stronger. To civilisation;-but North Europeans are more civilised but more drunken than South Europeans; West Africans, savages of a very low type who have long manufactured palm wine, are conspicuously more temperate than other savages. Parental or ancestral drunkenness;- - but savages whose parents and ancestors never had any drink, are the most drunken of all. Education;-what is there in the education of South Europeans and Jews which renders them so superior in this particular to North Europeans? Temperament;but how did differences in temperament arise if not through evolution? Advance what other hypothesis one will, and there are numerous exceptions ; this theory of alcoholic evolution, which is in accordance with all we know of evolution under natural and artificial conditions, alone covers all the instances. Surely, then, there is no escape from the conclusion that all races that have had access to alcohol and are temperate have become so through evolution-through the elimination of the unfit, the innately drunken.

Opium has been used for hundreds of years in India, for two centuries in China, for three or four decades in Burma. The evidence given before the late Royal Commission on Opium showed that opium is never or very rarely taken to excess by the natives of India; it is frequently taken to excess in China; the Burmans take it in such excess and perish in such thousands of it, that we, the English rulers of the country, are obliged to prohibit the use of opium in Burma to Burmans alone, while permitting it to other nationalities ; just as in Canada and Australia we are obliged to prohibit the use of alcohol to the natives alone, while permitting it to all other peoples.

Were acquirements transmissible, races that had longest used tobacco should crave most for it. As a fact, races to which it is newly introduced crave just as much for it as those who have used it longest. On the other hand, like chicken-pox-but unlike tuberculosis, malaria, alcohol, opium-tobacco is not death-dealing. As a consequence it is not a cause of evolution; races which have longest used it crave for it as much as those to which it has been newly introduced.

Biologists have sought far and wide for evidence for and against the transmission of acquired characters. All manner of uncanny experiments, generally difficult for the ordinary man to repeat, have been made on all kinds of strange animals. Guinea-pigs and white rats have been great sufferers. Had the experimenters turned to man, the proper study of mankind, their labours would have been needless. Had they considered the non-transmission of the effects of disease, surgical operations and chronic inebriety, a useless chapter in vivisection would not have been written. Had they considered the amplitude of man's physical and mental acquirements, they had scarce asked for proof more convincing.

Natural selection as a cause of evolution was alleged by Darwin. Thereupon his critics raised objections. First they declared there had been no evolution. They forgot how the races of mankind, though derived from a common origin, now differ each from all others. Next they said there was no such thing as natural selection. Nature, accord- 
ing to them, worked in an altogether haphazard way. The fittest did not survive. This view found especial favour in the eyes of two aristocratic and orthodox amateurs, the late Duke of Argyle and the present Marquis of Salisbury-politicians whose cabinet rank gave weight to their opinions on matters biological. Some professional biologists agreed with or followed them. Thereupon experiments to prove or disprove the actuality of natural selection were set agoing. Professor Wheldon has lately done to death many crabs; Professor Poulton has caused the elimination of many chrysalises. But under the eyes of Cabinet Ministers and Professors alike, touching perhaps their nearest and dearest, worked those great causes of Natural Selection, those great agents of the elimination of the unfittest, disease and narcotics. They sought for evidence of evolution! Drink and disease have produced evolution of such vast political and biological importance that the effects of all wars in all countries during all times fall into insignificance beside them.

Zymotic diseases may be divided into two classes which shade into each other. The first class comprises those diseases of which the pathogenic micro-organisms have their habitation entirely or principally in the human body; the second class, those of which the organisms inhabit principally the environment outside the human body, and to which a human prey is not necessary. Syphilis is an example of the first class; its micro-organisms inhabit wholly the human body, being communicated by one sufferer to another by direct contact only. They are therefore wholly parasitic, and parasitic on man alone. Malaria is an example of the second class; a human prey is not necessary to its microbes, which are abundant in many deserted or sparsely inhabited tracts, and are therefore largely saprophytic. ${ }^{1}$ Between the two extremes, between the wholly parasitic and the mainly saprophytic diseases, are a number of other zymotic disorders which resemble syphilis on the one hand, or malaria on the other, with respect to the incapacity or capacity of their microbes to exist apart from the human body. The microbes of measles, tuberculosis, chicken-pox, scarlatina, small-pox, influenza, etc., are all earth or air borne. They are not communicated by direct contact, and can therefore exist at least for a limited time away from the human body; but apparently they cannot multiply in the outside world. The microbes of cholera, typhoid, yellow fever, etc., and some other complaints, chiefly water borne, are able not only to exist outside the human body, but apparently can increase and multiply away from it. But they cannot thus multiply to an indefinite extent-at anyrate

\footnotetext{
1 I use the word saprophytic, as meaning merely that the microbes are capable of persistence for an indefinite period outside the body of man. The life-history of the malaria parasite is not thoroughly known. It is certain that it infests the mosquito, and Dr Patrick Manson believes that it infects man only through the mosquito. Lately he has extended his theory, and now states that the mosquito is infected through man alone. "Malaria would be stamped out in a community by all round free drugging with quinine. After a month or two the supply of infected hlood would have come to an end, and consequently there would be no more infected mosquitoes. "That is one way of exterminating malaria." If Dr Manson be correct, the malaria protozoon is strictly parasitic. But there are difficulties. If man is infected solely through the mosquito, why does the digging of malarious soil frequently start an epidemic of malaria? It is not to be supposed that infected mosquitoes are dug up. On the other hand, if the mosquito is infected solely through man, why are sparsely inhabited countries, such as certain jungle tracts in India and Assam, very malarious? There mosquitoes are so many, and men so few, that the former must rarely have the chance of being infected through the latter. Again on Dr Manson's hypothesis, it is difficult to understand why malaria varies so much in type with time and space.
} 
they cannot to an indefinite extent multiply away from water polluted by human excreta, for travellers in countries void of human inhabitants are not infected by them. They are saprophytic to a very limited extent only. Accordingly as diseases resemble in type syphilis or malaria, locality is of little or much importance. Syphilis, since it inhabits only the human body, is not affected by locality, and has therefore travelled everywhere, and is now of world-wide distribution. In this it is resembled by tuberculosis, measles, and other earth and air borne complaints. Cholera, yellow fever, etc., because more dependent on the outside world, are of more local distribution. Malaria, which is entirely dependent on the outer world, is strictly local; it does not travel all over the world, but infests certain welldefined tracts. ${ }^{1}$

Malaria and other saprophytic diseases, but chiefly malaria, have played a mighty part in the Natural and Political History of Man. Where malaria is mild, as in certains parts of North America, it is a grave deterrent, though not a complete bar to alien immigration. Where it is virulent, as in the Terai and on the West Coast of Africa, it acts as an absolute check to colonisation. In such countries, in exceptional instances, strangers from non-malarial regions may survive for years ; but as a rule they perish early. In any case they are unable to rear families. It is improbable therefore that the nations inhabiting the worst of these areas can have undergone the whole of their evolution within them; the death-rate of a non-evolved race being so high as to cause extinction, not evolution. They probably dwelt first within less malarious regions and underwent part of their evolution there. But now, after the sufferings of uncounted generations, after paying toll of millions of lives, they dwell secure in their fastnesses. They cannot be displaced by incoming hordes. They may be conquered by the superior weapons of civilisation, but even then, with the advance of their own culture, they must in time regain their freedom. Not for them is the fate of so many perished and forgotten

1 Bacteriologists have proved that the virulence of some diseases may be altered by changing the media in which the pathogenic micro-organisms exist. The same fact may be observed in nature. Syphilis, which has an unchanging environment, since it exists wholly in man, is very stable in virulence of type all the world over, and during long intervals of time-during intervals of time so long that any change of type must be attributed to the evolution of the race attacked, not to the increased or decreased virulence of the microbe attacking. Thus races which have long been afflicted by syphilis take the complaint mildly, but communicate it in a severe form to races that have had little or no experience of it. Phthisis, measles, whooping-cough, etc., are nearly as stable in type. But cholera, typhoid, and other water borne diseases, the microbes of which are subjected to the influence of the outer world to a greater extent, are much less stable. Malaria is exceedingly changeful. Subjected, as its microbes are, to all the influences of seasons and locality, it is mild at one time or in one place and severe in another. The microbes of disease multiply very rapidly, each microbe dividing into daughter cells. Bacteriologists have found that a character acquired by the mother cell (e.g., increased or decreased virulence) is frequently inherited by the daughter cells. It has been claimed that this constitutes an instance of the transmission of an acquirement. But the microbes of disease--unicellular plants and animals, each one capable of continuing the race-are germ-cells. The mother cell divides into daughter cells similar to itself ; and if, before division, the mother cell is changed in any way the daughter cells inherit the change. The case is quite different as regards multicellular plants and animals. The germ-cells of these are not daughters of the somatic cells. When a character is acquired by a multicellular being, the change occurs in the somatic cells, which are then supposed by the adherents of the doctrine of transmission to affect in some way the associated germ-cells. But even did the change in the germ-cells happen, it could not of course be of the same kind as that in the somatic cells. For instance, exercise multiplies muscle-cells and renders them capable of enduring fatigue, a change which from the nature of the case cannot occur in the germ-cells. On the contrary, the latter are supposed to be so changed that their very remote cell-descendants, the muscle-cells of the child, inherit the peculiarity the parent acquired. It is clear, therefore, that the transmission of an acquirement is not by any means the same thing in unicellular and multicellular organisms. It is likely enough to occur in the former; it is wildly improbable in the latter. 
races whose poor relics, rude implements and mouldering fragments of bone, alone attest their former existence, and tell of their extinction by stronger and fiercer invaders. They are safe for all time-unless, indeed, the march of sanitary science destroys malaria, still their scourge, but now also their principal rock of defence.

If malaria and its congeners have played a great part, tuberculosis and other wholly parasitic diseases have played a greater. Being wholly parasitic and earth and air borne, they are necessarily diseases of crowded populations. Among scattered and nomadic peoples they tend to die out unless renewed from denser communities. During the Stone Age they can but have little afflicted mankind. But for many thousands of years certain areas of the Old World, China, India, and the coasts of the Mediterranean have been thickly populated. In ancient as in modern cities the wholly parasitic diseases took toll of human lives, and age after age eliminated the unfittest. Our oldest records tell of plague and pestilence. With the advance of civilisation, as cities enlarged and multiplied, and the densely populated areas widened, the stringency of selection increased. The conditions became more and more favourable to the spread of infectious disease. Sanitation has done something in recent times, especially in England, yet even now, measles and tuberculosis, for instance, are so prevalent that no man escapes infection unless he be immune, or death unless he be resistant. As a result, evolution against purely parasitic diseases has proceeded very far. We speak of the west coast of Africa as having a deadly climate. It is deadly to us who have undergone no evolution against malaria. But just as deadly is the climate of our great cities to races that have undergone no evolution against tuberculosis and measles. South Sea Islanders and Esquimaux, for instance, perish as surely in London as Englishmen in West Africa. To judge by analogy our ancestors of the Stone Age must have been as susceptible to measles and tuberculosis as Red Indians and South Sea Islanders-as little capable of dwelling in dense communities and consequently of achieving civilisation. ${ }^{1}$ Our civilisation is therefore conditioned by our power of resisting certain infectious diseases, a power which arose during the advance of civilisation by a long and painful process of evolution.

Malaria infests a large portion of the earth's surface, but except in

1 Professor Hamilton thinks that " there is good reason to believe, that instead of man being an animal very prone to tuberculosis, he is extremely insusceptible, otherwise it is dificult to explain how tuberculosis has not utterly decimated the human race." As a fact it has decimated it. So far from man being insusceptible to the disease, all races that have not bern weeded out by it are extremely susceptible. He attributes the susceptibility to a "variation which took place far back in our history" which "has been propagated in the descendants ever since." But sissceptibility to tuberculosis was plainly no variation; it was the original condition-a condition which the races of the New World to their undoing still retain. The real variation was insusceptibility. The most resistant, not the most susceptible races have departed from the ancestral type. He added, "if you ask me in what the particular vulnerability consists, I should reply that, most likely, it resides in the epithelial coverings of the body being too little resistant, too easily stimulated by external agencies, too readily penetrated by the parasite of the disease." But it is not to be supposed that all the races of the New World are weaker as regards their epithelial coverings than, for example, Englishmen. Moreover, when the parasite gets past the epithelial protections of Englishmen, the disease very often takes on a chronic form and frequently the sufferer recovers. Acute phthisis usually supervenes in the Polynesians and Red Indians, who are often men of very fine physique, and they seldom recover. It is a favourite notion that the complexion of the skin has some relation to the phthisical diathesis. Blonde people are supposed to be peculiarly susceptible. But the New World races are all dark, and Negroes and Papuans, who are very susceptible, are absolutely black. I take it that it is not in the skin or other epithelial coverings that the resisting power to zymotic disease resides, but in the phagocytes, whose special function it is to resist bacteria. It is probable that the so-called phthisical facies is not a precedent but a consequent of the disease. 
the south of Asia its habitat, mainly the great tropical forests, is thinly populated. Tuberculosis, the type and the worst of purely parasitic diseases, afflicts a larger and more densely populated area. From time immemorial it has ravaged the Old World. It is not unknown in African forests and Indian jungles, and therefore Africans and Indians have undergone some evolution against it; but it has longest, or at least principally, afflicted parts of Western Europe and Eastern Asia, where for thousands of years teeming populations have lived in houses so designed for warmth as to be more or less exclusive of light and air. Like all or most infectious diseases, it was unknown among the scanty population of the Western Hemisphere till introduced from the Old World, whence came not only Old World diseases, but Old World conditions of life as well-teeming cities, air-tight houses and clothes, the best of all vehicles for the conveyance of infection. No gradual evolution, as in ancient Europe, was possible under such conditions. Extinction, swift or slow according to circumstances, was generally the only alternative. The unfit were so many and the fit so few that the aborigines dwindled. The Caribs and Tasmanians have gone. The Esquimaux and the Red Indians, the Patagonians, the Terra del Fuegians, the Australasians, the Polynesians, are going-the greatest and grimmest tragedy in all human history.

Writing of the Spanish occupation of the West Indies, the late Professor Froude says: "The Carib races whom the Spaniards found in Cuba and St. Domingo had withered before them as if struck by a blight. Many died under the lash of the Spanish overseers. Many, perhaps the most, from the mysterious causes which have made the presence of civilisation so fatal to the Red Indians, the Australians, and the Maoris. It is with man as it is with animals. The races that consent to be domesticated prosper and multiply; those that cannot live without freedom pine like caged eagles, or disappear like the buffaloes of the prairies. Anyway, the natives perished out of the islands of the Caribbean Sea with a rapidity which startled the conquerors. The famous Bishop Las Casas pitied and tried to save the remnant that were left. The Spanish settlers required labourers for the plantations. On the continent of Africa were another race, savage in their natural state, which would domesticate like sheep and oxen, and learnt and improved in the white man's company." These sentences are typical of much that has been written concerning the decay of the New World races. Almost all writers unite in speaking of it as mysterious, and yet the facts are patent, are manifest to every observer on the spot. There is no more mystery connected with their decay than with the extinction of the dodo or the bison. It cannot be doubted that the New World races have suffered or are suffering extinction in consequence of the introduction among them of Old World diseases, and of concentrated Old World forms of alcohol. So much is quite beyond dispute, and these causes may be seen in operation over half the world at the present day-in North and South America, in Australia, in New Zealand, and in the islands of the Pacific, as well as in the Andamans, and several other of the oceanic islands of the Eastern Hemisphere. The sole mystery has lain in the circumstance that the races of the New World are less resistant to diseases of the non-malarial type than those of the Old World, 
and to that mystery I trust I have furnished a key. It is no question of freedom or of domestication, or even of civilisation per se. The continental savages of the Old World do not perish when brought into contact with civilisation. In India and Ceylon are tribes of an exceedingly wild type that have existed for thousands of years in contact with, and in the midst of, most ancient civilisations and very crowded populations. There is no conceivable reason why the Caribs should have been less capable of enduring domestication or slavery or civilisation than the equally barbarous or even more barbarous negroes. But they perished, as other New World races are perishing, because, unlike the negroes, they had not been rendered resistant to the non-malarial zymotic diseases which the Spaniards introduced, and they would have perished had the Spaniards come among them as slaves, not as masters, and adopted their manners and habits of life, instead of forcing on them a change ; for their islands lay in the very highway of the commerce that then sprang up, in the very path of infection. The natives of tropical America seem destined to survive. Defended, like West Africans, by virulent malaria, they are not brought into close contact with Europeans, who cannot as colonists spread over the country in millions, as in North America and Austral.. asia. Consequently, though these races have suffered greatly from measles, smallpox, and other air-borne diseases, yet from tuberculosis, the most death-dealing of all diseases, they have suffered comparatively little. They owe their salvation, besides, to the smallness of their communities, and to the fact that the warmth of the climate renders pleasant the admission of plenteous air to their dwellings.

See then how the matter stands. Were acquirements heritable, races that had longest been afflicted by malaria or tuberculosis would be the weakest against them. In that case malaria, the microbes of which are mainly saprophytic, would destroy all human life within the areas infested by them. Tuberculosis, the microbes of which are entirely parasitic, mainly on man, would render all dense populations, and therefore all civilisation, impossible. But to rise to the full height of this great argument, consider in this relation the position of the Anglo-Saxon race. Its ancient home was in the British Isles, where under stringent selection it evolved for centuries against purely parasitic diseases. By rare good fortune its emigrants went mainly to land undefended by virulent malaria and unprotected by evolution against purely parasitic diseases. Unchecked by malaria the Anglo-Saxons spread; smitten by parasitic diseases the aborigines dwindled. To-day the former hold so large and fertile a portion of the earth's surface that their predominance in the future is assured. They may be beaten in war ; they may break into separate governments ; but disease cannot now exterminate them, and their increasing numbers must secure the ultimate victory. The Latins, especially the Spanish and Portuguese, were less fortunate. They had the first start in the race, and they chose the seemingly richer tropics. But, checked by malaria, their diseases did not always exterminate the natives; and even where the latter did perish, as in the West Indies, their places had to be filled, not by pure Latins, but by half-breeds, and especially negro slaves imported from West Africa. All these communities have revolted, and Hayti is now a Negro Republic, foreshadowing the fate of our Indian and West African conquests. The Latins conquered, 
but in a real sense could not colonise. The experience of the AngloSaxons in other parts of the world is similar. They can colonise South Africa because it is not defended by virulent malaria, but they must share its possession with the natives, who have undergone evolution against parasitic diseases, and are not exterminated thereby. To West Africa and India, the homes of malaria, they can go only as conquerors. One day the natives when sufficiently civilised, will certainly expel their masters. Alcohol, as well as microbic disease, has helped. The natives of India and A frica, who from very ancient times have manufactured solutions of alcohol strong enough to be poisonous, having suffered previous elimination, are not now exterminated by spirits. Moreover, the natives are protected by opium, the use of one powerful narcotic being a bar to the extensive use of any other. But given the opportunity, the natives of the New World drink to extinction. In the savage past races exterminated each other with the sword. Now they do it with disease. And the work done by disease is greater far than aught ever done by the sword.

Historians have chronicled how Jew and Saxon slew the Canaanite and Briton and entered into their inheritance. They tell us with vast amplitude of detail of little, and well-nigh purposeless wars, of futile changes of dynasties, and so forth. They give us low gossip concerning kings and queens. But of this momentous march of disease, which has for ever changed the political face of the world, they tell us nothing. Biologists and philosophers have expended vast learning and labour in tracing the evolution of hoof or of tail. They are nearly all agreed that evolution is caused solely by the elimination of the unfittest. For thousands of years diseases due to micro-organisms or to the use of powerful narcotics have been the main cause of human elimination, and therefore of human evolution. But of this great process and its tremendous consequences biologists are silent. Anthropologists have carefully differentiated the races of mankind, recording minute variations in size, shape, colour, hair, and features. But they have quite ignored the most important of all human differences. Medical men have a monumental literature on disease as it affects the individual; on disease as it affects the race they have published scarce a volume. But no theme more august could have engaged the pen of any writer. They have examined man through a microscope, as it were, but a wider view is also necessary. Elaboration of detail is imperative; but by an extended survey much may be learned which the study of minutia cannot furnish.

Heredity, obviously important from a scientific and theoretical standpoint, is not without its practical bearings. ${ }^{1}$ No philanthropist who has at heart the well-being of aboriginal races can afford to neglect its teachings. The savages of the Old World, the negroes, for instance, are capable of civilisation; in other words, having undergone evolution against parasitic diseases, they are capable of persistence under the ordinary conditions of civilised life. Not so aborigines of the New World.

1 It concerns the question of temperance reform very closely, but on that I have written at length elsewhere, and am glad to have escaped with my scalp. Reformers are proverbially energetic. Gentlemen who have not thought it worth while to contest my premises have discovered that I am greviously lacking in good sense and ordinary morality. One reverend gentleman compared me to Satan and Judas Iscariot, with a judicial leaning to Satan. He suggested, however, that I might with advantage increase my resemblance to Judas by imitating him in the last act of his unworthy life. 
The success of African missionaries has no counterpart in the Western Hemisphere, at any rate in such parts of it as are not affected by virulent malaria. Many observers in Polynesia have noted that the establishment of a mission is frequently followed by the more or less rapid extinction of the congregations. When we remember that all missionaries build churches and schoolhouses, wherein their flocks are crowded, and insist on the wearing of clothes, the result is not surprising. The natives are placed under conditions the most favourable for the spread of zymotic disease. Is it too much to hope that natives may be converted in the open air, and that the wearing of garments is not a necessary prelude to eternal bliss? Occasionally clergymen with incipient phthisis adopt a missionary career in the double hope of benefiting themselves physically and the heathen spiritually. In the pure air and sunshine of Pacific Islands they often recover. But phthisis is an infectious disease, and Pacific Islanders are less resistant than the least resistant of Europeans. Under such circumstances we may reasonably expect a religious minded pastor to manifest gratitude and admiration for restoration to strength at the very moment when his flock, mysteriously smitten, most needs his ministrations. The situation in the South Seas is pitiful, but occasionally it is not devoid of a grim humour.

As I have already intimated, it is not possible to consider the whole question of heredity within the limits of a magazine article. The subject is too big even in its medical aspects. I trust, however, even in the foregoing sketch, I have not altogether failed in my endeavour to demonstrate its importance. To sum up: it is highly improbable, from developmental reasons, that acquired characters can be transmitted; no single instance of such transmission has ever yet been proved; no body of men possess evidence on this point so overwhelming as medical men, but the evidence in their hands has generally been neglected or misunderstood ; properly used, it supplies matters of the highest importance concerning the Natural and Political History of Man.

\section{THE USE OF ICHTHYOL IN VETERINARY PRACTICE ${ }_{n}{ }^{1}$}

By EugEn Bass, Veterinary Surgeon, Görlitz, Germany.

IN view of the large number of new medicines which have been introduced during recent years, the practitioner who has not access to all the different journals must find it an advantage to learn whether the expectations excited by the discovery or introduction of different therapeutic agents have been fulfilled in practice, and this he may do by the perusal from time to time of articles collated from the whole of the current literature on the subject. It is therefore my intention to discuss in a series of articles, appearing at convenient intervals, the different medicinal substances which have been introduced into veterinary practice during the last twenty-five years, and to show whether they have achieved in practice the results that were claimed

1 This article appears simultaneously in the "Deutsche Zeitschrift fur Thiermedicin." 